\title{
LHomme
}

L'HOMME Revue française d'anthropologie

$183 \mid 2007$

Comment être parents ?

\section{Lila Abu-Lughod, Dramas of Nationhood: The Politics of Television in Egypt}

Chicago-London, University of Chicago Press, 2004, 319 p., bibl., index, ill.

\section{Kristina Tiedje}

\section{(2) OpenEdition \\ Journals}

Édition électronique

URL : http://journals.openedition.org//homme/9811

DOI : 10.4000//homme.9811

ISSN : 1953-8103

Éditeur

Éditions de l'EHESS

Édition imprimée

Date de publication : 1 septembre 2007

Pagination : 235-236

ISSN : 0439-4216

Référence électronique

Kristina Tiedje, «Lila Abu-Lughod, Dramas of Nationhood: The Politics of Television in Egypt », L'Homme [En ligne], 183 | 2007, mis en ligne le 28 juin 2007, consulté le 24 septembre 2020. URL : http:// journals.openedition.org//homme/9811 ; DOI : https://doi.org/10.4000//homme.9811

Ce document a été généré automatiquement le 24 septembre 2020

〔c École des hautes études en sciences sociales 


\section{Lila Abu-Lughod, Dramas of Nationhood: The Politics of Television in} Egypt

Chicago-London, University of Chicago Press, 2004, 319 p., bibl., index, ill.

\section{Kristina Tiedje}

1 Quel est le rôle des médias dans les débats culturels sur les identités nationales, religieuses et sociales? Dramas of Nationhood nous donne un exemple notable d'anthropologie de la place des médias de masse dans l'imagination sociale des personnes. Par cette étude - «non exotique » par excellence -, l'anthropologue Lila Abu-Lughod écrit «contre la culture » se concentrant sur des conversations et des débats dans lesquels des idées culturelles sont formulées et distribuées, plutôt que partagées. Il s'agit d'interpréter les cultures après l'avènement de la télévision, télévision qu'elle utilise pour entrer dans la vie de ses interlocutrices et interlocuteurs. Lila Abu-Lughod examine en effet les textes et les savoirs culturels construits à partir des feuilletons de la télévision nationale égyptienne, diffusés durant le mois du Ramadan. Ainsi, ce n'est pas le pouvoir des textes culturels diffusés qui font objet de cette étude, mais l'engagement et la production de sens des spectateurs à partir de ces textes culturels.

2 Les questions qui ont animé sa recherche sont emblématiques d'une anthropologie critique : quel est le rôle de la culture de la télévision dans l'hégémonie de l'État-nation, par rapport aux forces de la mondialisation, au développement et aux idéologies nationalistes? Le contexte égyptien est particulièrement riche car la télévision fut longtemps un instrument de diffusion des idées nationalistes et « développementalistes », depuis sa création en 1960. À l'époque, elle servait davantage pour « créer des citoyens » et pour diffuser des messages en vue d'« éduquer » la nation (voir préface, p. x). Or, depuis les années 1990 (quand Lila Abu-Lughod a débuté son étude), l'ouverture de l'Égypte à l'économie de marché a entrainé un changement non négligeable des programmes télévisés. Les téléspectateurs sont désormais des clients. 
Les feuilletons et les séries dramatiques s'adressent aux consommateurs potentiels et non aux citoyens. Néanmoins, et Lila Abu-Lughod le montre bien, la nation demeure le domaine principal de production de sens dans les négociations identitaires des Égyptiens.

3 Cet ouvrage offre une description approfondie (thick description) de la télévision, qui, en étant abordée comme objet anthropologique, permet d'écrire à la fois sur le transnational, le national, le régional, le local et le personnel. Parmi les études sur les médias de masse, la démarche de Lila Abu-Lughod est novatrice puisqu'elle nous présente les négociations identitaires (ce qu'elle nomme les « débats égyptiens ») des personnes qui sont les citoyens de cet État-nation postcolonial dans un monde changeant et dans des contextes différents. Son approche méthodologique multisituée rend compte de la diversité des représentations de la nation à partir de trois sites et auprès de trois types de populations différentes: d'abord, auprès de dramaturges, écrivains, critiques et managers des feuilletons qui décident de ce qui sera diffusé ; puis, de villageois d'Égypte du Nord vivant de l'industrie touristique; et enfin, de femmes pauvres d'origine rurale installées au Caire pour travailler comme employées de maison.

4 L'organisation de l'ouvrage en trois parties («Anthropologie et médias nationaux », «La pédagogie nationale» et «Une hégémonie qui disparaît: le développementalisme ») permet de confronter et de faire dialoguer les représentations de l'élite avec celles des subalternes; elle permet une analyse approfondie des enjeux de pouvoir entre les dominants et les dominés. La télévision produit des textes culturels transposés dans des contextes culturels différents. Les histoires de la télévision "commencent à prendre leur indépendance ». D'un côté, nous approchons les représentations des intellectuels des villes et des agents de l'État à l'égard des ruraux vus comme des ignorants (faute d'éducation). De l'autre côté, l'imaginaire de la nation se révèle multiple dans le temps et dans l'espace. Lila Abu-Lughod montre avec finesse que les téléspectateurs ruraux et les employées de maison du Caire sont des sujets modernes et cosmopolites: d'abord ils sont conscients des idéologies diffusées par la télévision, et puis, ils réagissent par rapport à ces dernières (que ce soit avec hostilité ou avec sympathie). Les téléspectateurs égyptiens ne sont pas des sujets «non modernes » et dominés par les idéologies de l'État, mais ils connaissent davantage les différents modes de vie et s'interrogent sur leur propre place au sein d'un monde global, dans une Égypte mondialisée.

5 Les disjonctions du monde global s'affichent aussi par la multiplicité des thèmes des feuilletons, qui peuvent entrer en contradiction (il y a par exemple des séries proislamiques et des séries pro-développement). À quel modèle appartient alors le « citoyen consommateur » dans un tel paysage télévisé ? Lila Abu-Lughod montre que la nation égyptienne souffre d'une division profonde vraisemblablement aggravée par ce "réalisme capitaliste " des séries télévisées qui diffère totalement des réalités vécues des employées de maison en ville et des ruraux pauvres. La juxtaposition des mélodrames et des publicités à la télévision égyptienne provoque des ambivalences au sein des spectateurs, ce que Lila Abu-Lughod nomme des « idéologies alternatives ». Les réponses des spectateurs sont formulées en fonction du décalage entre ces "réalités " dramatiques des feuilletons et la vie quotidienne des personnes. Son regard critique met en lien ces mondes juxtaposés afin de comprendre l'intimité et l'ambivalence des spectateurs avec la nation. Les séries télévisées contribuent à " naturaliser la nation » 
(notamment par l'identification des téléspectatrices aux «stars »). Et pourtant, elles renforcent l'image de la nation divisée, marquée par les inégalités. Mais c'est notamment cette ambivalence qui permet à la télévision de devenir le contexte (setting) à partir duquel les citoyens donnent leur avis sur «ce que devrait être la nation", sur "quelles devraient être les responsabilités du gouvernement", et sur "qui devrait avoir accès à toutes ces marchandises mises à la disposition d'un pourcentage minime de la nation ». Les citoyens marginaux racontent leurs histoires en comparant leurs réalités sociales et économiques aux visions diffusées qui prend la nation comme cadre de référence. Finalement, c'est toujours la nation qui se trouve à la base de leurs identités.

\section{AUTEUR}

\section{KRISTINA TIEDJE}

Université Lumière Lyon-2, Faculté d'Anthropologie, Bron.

kristina@ktiedje.com 